\title{
EXPLORING GRADUATE EMPLOYABILITY IN RELATION TO THEIR ENGLISH LANGUAGE PROFICIENCY: A PRELIMINARY STUDY
}

\author{
${ }^{1}$ KAMSILAWATI KAMLUN \\ ${ }^{2}$ ESTHER JAWING \\ ${ }^{3}$ JUALANG BIN ABDULLAH GANSAU
}

${ }_{1 \& 2}$ Pusat Penataran Ilmu dan Bahasa, Universiti Malaysia Sabah, Jalan UMS, 88400 Kota Kinabalu, Sabah

${ }^{3}$ Fakulti Sains dan Sumber Alam, Universiti Malaysia Sabah, Jalan UMS, 88400 Kota Kinabalu, Sabah

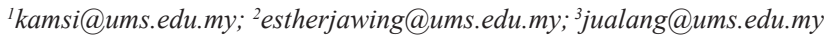

Tarikh Diserahkan: 25 November 2020 / Tarikh Diterima: 6 Disember 2020

Abstract Recent literature has suggested that the relationship between globalisation and English language proficiency implicates employability in the job market. However, it could differ in different occupational groups as well as in different countries. Therefore, this study aims to investigate whether there is an effect on the graduate's employability based on the student's English language proficiency and their Malaysian University English Test (MUET) results. A total of 8,995 graduates who graduated in 2015 and 2016 were surveyed using data from the feedback method administered by the Ministry of Higher Education Malaysia from the Graduate Tracer Study 2015. The model used in this analysis would test the hypothesis as to whether there is a significant association between English language proficiency based on their MUET outcomes and their English language proficiency courses with the job status of UMS graduates in relation to their English language proficiency. In order to classify factors that influence graduate employability, an extensive analysis of the current literature is also used. For both local and global higher education contexts, the conceptual structure developed for this study applies. The knowledge offers insights into the growth of student employability and support needs for students to improve their graduate employability.

Keywords: Graduate employability, employment status, English language proficiency, MUET. 


\section{INTRODUCTION}

Global higher education and business have been characterised in recent years by a growing interest in the idea of graduate employability. One of the factors that assess an institution's effectiveness is therefore the employability of its graduates. Graduate quality is very much a reflection of a feature of quality training and facilities since it helps to ensure that graduates are prepared with the requisite expertise, skills and values that will enable them to operate in their respective fields. The relationship between globalisation and English language proficiency implies employability in the job market is one of the key issues highlighted in the literature as well as posed by the industry. A competitive job market requires strong communication skills in the workplace, according to Dustmann and Fabbri (2003). As a consequence, English plays a vital role in the workplace as a medium of communication. In the local academic context, specifically at Universiti Malaysia Sabah (UMS), there is undeniably a need to conduct a thorough exploration of this issue.

In UMS context, MUET results are used as an entry criterion before joining the university and are often used to classify students taking English language courses at the Centre for the Promotion of Knowledge and Language Learning or Pusat Penataran Ilmu dan Bahasa (PPIB). For students who attained Band 3 upper (160-179) to Band 6, they will sit for Advanced English, whereas those who have achieved Band 1 to Band 3 lower (140-159) would have to attend English Language proficiency courses. In the case of this study, only students who have completed language proficiency courses are selected. This is because they are expected to attend four English Language proficiency courses for four semesters in order to fulfil the graduation criteria.

Therefore, the purpose of this survey is to explore the graduate employability in relation to their English Language proficiency. This will be investigated whether there is a significant relationship between graduate employability in relation to their English language proficiency based on their MUET results and their English Language proficiency courses results. 


\section{RESEARCH OBJECTIVE}

The overall objective of conducting this study is to investigate whether the English Language courses results and MUET results has an effect on the student's graduate employability. The specific objectives are:

1. To examine whether there is an effect on the graduate employability based on their English Language proficiency courses results; and

2. To examine whether there is an effect on the graduate employability based on their MUET results.

\section{LITERATURE REVIEW}

For the service industry, individuals with good communication and interpersonal skills are important. Unfortunately, our local graduates lack these qualities. First of all because Bahasa Melayu is the official language and the teaching of almost all subjects at all levels, including primary and secondary schools as well as tertiary levels, is not entirely in English, it is difficult for some local graduates to communicate in English when they enter the job market (Noor Azlina, 2011). Various studies showed that employers place greater emphasis on employees' communication skills in all occupational fields than on academic achievements (Maes, Weldy \& Icenogle, 1977; McPherson, 1998; Winterbotham, Adams \& Kuechel, 2001).

While much attention is given to academic and employability, many have argued that many types of research concentrate on employability on a theoretical and prospective basis, which lacks the empirical evidence to support these theoretical prepositions. Moreover, studies have focused on case studies that cannot be generalised (Wickramasinghe \& Perera, 2010). As a consequence, the effects are hard to extrapolate. The research field has been established in this respect by researchers to investigate the transfer of graduates while they are out at work (Holden \& Hamblett, 2007). Through this particular survey, it is hoped that it will add to the body of information on graduate employability from an individual perspective by evaluating or exploring the significance of factors assessed by recruiters when assessing new graduates. 
In past research studies, the importance of good command of English to employees has also been emphasised. English is a medium to connect internationally with more businesses. Pandey and Pandey (2014) claimed that when an interview is concerned, English is typically used to perform an interview session, where employers also make their decisions on the interviewees' ability to talk in English. They also added that an employee would usually stay at the bottom of the leadership ladder with great ideas but with weak English order. In addition, several studies have also shown the value of communication skills for career development in Malaysia (Lie, Pang \& Mansur, 2009).

The English at Work: Global Workplace Language Skills Study (2016) survey results showed that English language skills are essential for over 95 per cent of employers in many non-native English-speaking countries. There are a multitude of English requirements in countries where English is not a native or official language, with seven per cent of job tasks requiring native-level English, 49 per cent requiring advanced English, 33 per cent requiring intermediate English, and eight per cent requiring basic English. The results showed that there is a difference between the requisite English language skills and the currently available skills in every industry. Interestingly, there is no difference between large, medium-sized and tiny employers. In all organisational sizes, there is at least a 40 per cent English skills shortage. The findings are based on data from 5,373 employers in 38 countries who finished the annual QS Global Workplace Survey.

Eldeen, Abumalloh, George and Aldossary (2018) point out that training and providing graduates with the skills needed to meet the needs and requirements of the labour market is one of the basic tasks of education. However, according to Anas and Hamzah (2017), due to the rapid introduction of new technology, economic crises and sectors, the labour market is evolving over time. Therefore, to be employable, many graduates are sought out by employers on the basis of academic credentials, experience, various skills in different fields, expertise, competence, competence, strength, attitude and aptitude. 
Thus, it is therefore necessary to increase our understanding of the factors that influence the effective transition of undergraduate university students to the labour market. This is to reduce the proportion of overqualified new graduates as well as to ensure that in the twenty-first century, employers will recruit graduates who have the skills required by organisations. In a survey conducted by McKinsey (2012), 40 per cent of employers indicated that there is a large skills gap between graduates and entry-level requirements. He also concluded that there is an issue with education systems that do not generate potential employees with the kinds of skills required by today's organisations, let alone those of tomorrow (McKinsey \& Company, 2012: 23).

\section{METHODOLOGY}

This study applied a quantitative approach. The data used in this study were collected from three different sources: the 2015 Graduate Tracer Study which was conducted upon graduation by the Ministry of Higher Education of Malaysia, data from the Centre for Industry and Community Network (CICN) in UMS, and data from the UMS Academic Division Department. The National Graduates Tracer Research was first initiated and organised in 2002 by the Economic Planning Unit (EPU), Department of Prime Minister. However, the research was taken over by the Malaysian Ministry of Education (MOE) between 2003 and 2004, before being forwarded to the Ministry of Higher Education (MOHE) (Nordin Kardi et al., 2009).

For the purpose of this survey, the results (Cumulative Grade Point Average) of the student's English Language proficiency from the Academic Division Department, such as MUET and English Language proficiency courses, were correlated with their job status obtained from the 2015 Graduate Tracer Study. Samples used in this study were 8,995 respondents from 14 different faculties in UMS who graduated in 2015 and 2016. Since this was only a preliminary analysis before embarking on a larger-scale study, only data from 2015 and 2016 were selected. The data were evaluated using statistical analysis and based on the average score (CGPA) obtained in the English Language proficiency courses and the MUET score (CGPA) in both years. 


\section{RESULTS AND DISCUSSIONS}

The profile distribution of the respondents is shown in Table 1. As far as jobs are concerned, 39 per cent of the total respondents were employed in 2015 and 52 per cent were employed in 2016.

Table 1 Respondents' profile

\begin{tabular}{|c|c|c|c|}
\hline & Category & Total & Percentage (\%) \\
\hline \multirow{3}{*}{ Employment Status 2015 } & Employed & 1361 & 39.0 \\
\cline { 2 - 4 } & Unemployed & 2099 & 61.0 \\
\hline \multirow{3}{*}{ Employment Status 2016 } & Employed & 1920 & 52.0 \\
\cline { 2 - 4 } & Unemployed & 1789 & 48.0 \\
\hline
\end{tabular}

Figure 1 and 2 demonstrate that the student's results depended on their status of employability in the years 2015 and 2016. However, the focus of the preliminary analysis was primarily on the outcomes of the PPIB English Language courses and MUET as a determinant of graduate employability for both years.

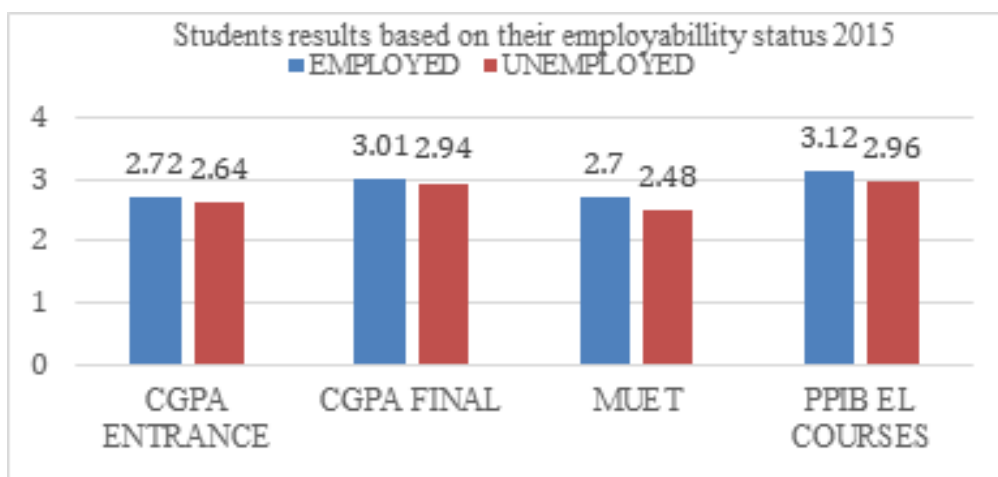

Figure 1 Students results based on their employability status in 2015 


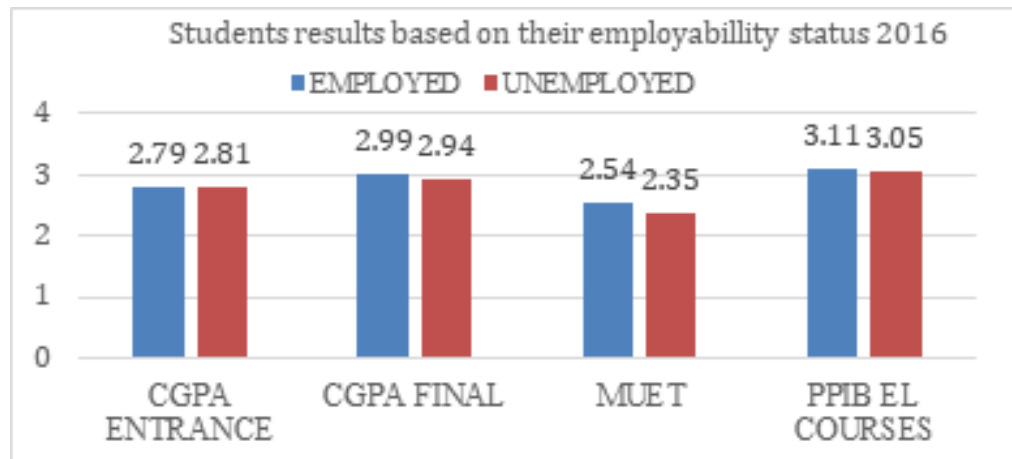

Figure 2 Students results based on their employability status in 2016

Using the results (CGPA) obtained in both MUET and English Language courses taken at PPIB, the relationship between the results of English language proficiency and the job status of the graduates in 2015 and 2016 was examined. The findings indicate that there is connection between the results and the employment status. The findings suggest that there is an effect on employed and unemployed graduates in terms of the results obtained in the MUET and English Language courses. The results are shown in the above figures.

\section{Results comparison: PPIB English Language Courses results based on graduate employability status}

The results show that the results of PPIB English courses among graduates who are employed and unemployed are related. This is seen in Figure 3 and 4, whereby those who are employed obtained an average of CGPA 3.12 and those unemployed obtained a CGPA of 2.96 in 2015. In 2016, the average score of those who are employed obtained a CGPA of 3.11 and those unemployed obtained a CGPA of 3.05. Therefore, as a determinant of graduate employability, there is a substantial connection in terms of the results obtained in English Language courses. Through this result, it can be assumed that higher CGPA has an effect on graduate employability. However, the gap is just marginally small, at 0.16 per cent in 2015 and 0.06 per cent in 2016 . 


\begin{tabular}{|l|c|}
\hline \multicolumn{2}{|c|}{2015} \\
\hline \multicolumn{1}{|c|}{ Status } & Average EL courses CGPA \\
\hline Employed & 3.12 \\
\hline Unemployed & 2.96 \\
\hline
\end{tabular}

Figure 3 PPIB English Language courses results in 2015

\begin{tabular}{|l|c|}
\hline \multicolumn{2}{|c|}{2016} \\
\hline \multicolumn{1}{|c|}{ Status } & Average EL courses CGPA \\
\hline Employed & 3.11 \\
\hline Unemployed & 3.05 \\
\hline
\end{tabular}

Figure 4 PPIB English Language courses results in 2016

\section{Results Comparison: MUET Results Based on Graduate Employability Status}

The findings indicate that those who are employed obtained an average CGPA of 2.74 and those unemployed obtained a CGPA of 2.48. This indicates that, as shown in Figure 5 and 6, the MUET results among graduates who are employed and unemployed showed an impact of 0.26 per cent in 2015 and 0.19 per cent in 2016. This depicts that the students with higher bands in MUET are more likely to be hired than those with lower bands. However, the gap is a marginally small percentage as a determinant of graduates' employability.

\begin{tabular}{|l|c|}
\hline \multicolumn{2}{|c|}{$\mathbf{2 0 1 5}$} \\
\hline \multicolumn{1}{|c|}{ Status } & Average MUET \\
\hline Employed & 2.74 \\
\hline Unemployed & 2.48 \\
\hline
\end{tabular}

Figure 5 MUET results in 2015

\begin{tabular}{|l|c|}
\hline \multicolumn{2}{|c|}{$\mathbf{2 0 1 6}$} \\
\hline \multicolumn{1}{|c|}{ Status } & Average MUET \\
\hline Employed & 2.54 \\
\hline Unemployed & 2.35 \\
\hline
\end{tabular}

Figure 6 MUET results in 2016 
It could therefore be summarised that the results of the English Language courses, as well as the results of MUET through their CGPA, play a significant role, although in a small proportion, in determining graduate employability. The reason may be that, aside from their English language skills, there may be other contributing factors to graduate employability. In relation to this the study stressed that there must be a discrepancy between what the industry wants and the curriculum. Consequently, a precautionary measurement should be taken to make graduates more employable. According to Kamlun and Shak (2014), the subject-specific approach should inspire learners to learn because it is focused on the specific needs of students for future occupational roles. On the other hand, some students might find their experience in an English for Specific Purposes classroom can be boring in terms of certain subject matter. Therefore, it is crucial to get the students' feedback in order to examined whether the course content suit their needs and educational goals.

Thus, this preliminary study will extend its focus on the need for the academic environment to deliver quality education and to ensure the skills acquired by the students should support their requirement to access the workplace and attain employment. It is hoped that with the retrofitted modifications in the curriculum it will lead to an effective change in improving the graduate employability.

\section{CONCLUSION}

To conclude, the Ministry of Higher Education of Malaysia has aggressively embarked on a mission to take on students and improve their communication and growth of soft skills to produce high-quality graduates with skills that are competent, competitive, creative and play an innovative role and step in line with the requirements of the country's industry and social needs. In relation to this, Zainuddin, Siti Zaidah, Pillai, Dumanig and Phillip (2019) also stated that employers and learners accept that English plays a significant role in employability. Although all parties agreed in general that good grammar and a wide range of vocabulary are significant, the results suggested many mismatches in terms of the perceptions of students and 
the expectations of employers. Therefore, the challenge of generating a highly skilled workforce in Malaysia will rely primarily on the different stakeholders in both the education system and the sectors involved. Using highly qualified employees would contribute to a more robust economic growth of the country.

The limitation of this study is that data analysed were only in 2015 and 2016 as it is a preliminary study before embarking on a broader scale which will involve students graduating after 2016 onwards. The approach used is therefore appropriate from the preliminary study to collect data that can be used to analyse the current status of graduate employability at UMS.

\section{REFERENCES}

Anas, I., \& Hamzah, S. R. (2017). Conceptual study on the enhancement of employability among undergraduates in work-based learning settings. Special issue - 4th International Conference on Educational Research and Practice. International Journal of Academic Research in Business and Social Sciences, 7.

Dustmann, C., \& Fabbri, F. (2003). Language proficiency and labour market performance of immigrants in the UK. The Economic Journal, 113(489), 695-717.

Eldeen, A. I. G., Abumalloh, R. A., George, R. P., \&Aldossary, D. A. (2018). Evaluation of graduate students employability from employer perspective: Review of the literature. International Journal of Engineering and Technology, 7(229), 961-966.

English at Work: global analysis of language skills in the workplace. (2016). [e-book] Cambridge English. Retrieve from http://www.cambridgeenglish. org/images/335794-english-at-work-executive-summary.pdf.

Holden, R., \& Hamblett, J. (2007). The transition from higher education into work: Tales of cohesion and fragmentation. Education and Training, 49(7), $516-585$.

Kamlun, K., \& Shak, P. (2014). student's feedback on the integration of grammar units and occupational topics in their grammar in practice course: A pilot study. Procedia-Social and Behavioral Sciences, 134, 220-225.

Lie, K. Y., Pang, V., \& Mansur, F. (2009) Employer perceptions on graduate literacies in higher education in relation to the workplace. English for specific purposes world. Retrieved from http://www. esp-world. info/Articles_20/ DOC/Koo_vp_employer_Jour nal18Oct09. 
Maes, J. D., Weldy, T. G., \& Icenogle, M. L. (1977). A managerial perspective: Oral communication competency is most important for business students in the workplace. Journal of Business Communication, 34, 67-80.

McKinsey \& Company. (2012). The state of human capital 2012: False summit - why the human capital function still has far to go. Research Report No. R-1501-12-RR, New York, NY, 23.

McPherson, W. (1998). Student perception about business communication in their careers. Business Communication Quarterly, 61(2), 68-79.

Noor Azlina Ismail. (2011). Graduates' characteristics and unemployment: A study among Malaysian graduates. Journal of Business and Social Science, 2(16), 94-103.

Nordin Kardi, Rosna Awang Hashim, Nurahimah Mohd. Yusoff, Shahizan Hassan, Nor Hayati Ahmad, Hanizan Zalazilah, Azlan Yahya \& Izham Shafie. (2009). Enhancing employability initiatives: Malaysia experience. Country Reports - Enhancement of Graduate Employment. 2009 ASAIHL Conference, 7-18.

Pandey, M., \& Pandey, P. K. (2014). Better English for better employment opportunities. International Journal of Multidisciplinary Approach and Studies, 1(4), 93-100.

Wickramasinghe, V., \& Perera, L. (2010). Graduates', university lecturers' and employers' perceptions towards employability skills. Education and Training, 52(3), 236-244.

Winterbotham, M., Adams, L., \& Kuechel, A. (2001). Evaluation of the work-based learning for adults programme since April 2001: Qualitative interviews with ES staff, providers and employers. Sheffield: DWP.

Zainuddin, Siti Zaidah, B., Pillai, S., Dumanig, F.P., \& Phillip, A. (2019). English language and graduate employability. Education \& Training, 61(1), 79-93. 
